\title{
Quadriplegic Bedridden Patients Improving Activity of Daily Living Using Technology: Inner Experiences
}

\author{
Nadia Crivelli ${ }^{1}$, Monica Consonni ${ }^{1 *}$, Giulia Zanaboni ${ }^{1}$ and Lidia Borghi ${ }^{2}$ \\ ${ }^{1}$ Department of Neuroscience, Italy \\ ${ }^{2}$ Department of Health Science, Italy
}

Submission: August 27, 2018; Published: October 25, 2018

*Corresponding author: Monica Consonni, Department of Neuroscience, ASST Grande Ospedale Metropolitano Niguarda, Italy; Tel: +39 3932010888; Email: monicaconsonni11@gmail.com

Abstract

Background: Cervical Spinal Cord Injury and bedridden periods may cause impossibility to participate and lack of motivation, affecting the rehabilitation process.

Purpose: To examine whether an occupational therapy intervention based on early introduction of relations and communication through multimedia and technological activities affects the participation perception of patients in their life.

Method: The qualitative and exploratory study was conducted in the Milan Spinal Cord Unit, during 2016. Six quadriplegic people willing to participate to the activity were enrolled. A month after the treatment, each participant was interviewed to explore their feelings and thoughts on their experience and their satisfaction.

Findings: Various themes emerged from the interviews: reduced privacy, loss of environmental and self-control, contact with social and physical environment, an increased possibility to participate and choose for themselves.

Implications: The possibility to participate actively to tailored ADL highlighted and the importance of an early intervention focused on quadriplegic deprived people.

Keywords: Occupational Therapy; Quadriplegia; Spinal cord injury; Multimedia devices

\section{Introduction}

Traumatic spinal cord injury (SCI) is a relatively rare event (global incidence rates ranges widely from 8 to 246 cases per million population) [1]. However, SCI may result in neurological damage causing permanent disability, and it may affect participation in work and quality of life. An Italian epidemiological study, conducted in 37 specialised centres in 2008 by GISEM (Gruppo Italiano Studio Epidemiologico Mielolesioni) revealed 1014 new cases of Spinal Cord Injury in two years, with an average age of population affected between 10 and 40 years. It is reported that the proportion of neck injuries causing a Cervical Spinal Cord Injury (CSCI) is growing worldwide (around 55-60\% of all traumatic SCIs) [2].

In Italy, a study conducted between 2008 and 2009 by Area Sanità e Salute della Fondazione ISTUD on a sample of 218 people affected by SCI, has showed that $42 \%$ has a CSCI (31\% affected by C1-C4 injury and 69\% has a C5-C8 lesion), while the remaining $58 \%$ is affected by paraplegia [3]. CSCI people, especially during the acute phase, experience disorders of occupation which are described as occupational deprivation and occupational imbalance [4]. The patient spends weeks or months in hospital beds with the risk of reducing socialisation and affecting mental status and the remaining part of physical ability.

This kind of environment can be conceived as adverse because the patient is not enabled to perform any activity. This situation has an impact on social roles and human participation with a negative effect on working life, entertainment, productiveness, privacy and care of the self. Occupational balance must be restored as soon as possible in order not to cause social and mental discomfort to the quadriplegic person [5]. In fact, illness is linked to lack or deprivation of occupation which has often been used as a measure to describe the health status $[6,7]$.

After such a trauma, self-image is modified and the distance between memory and reality seems to be unbridgeable [8]. During the first months of hospitalisation, a quadriplegic person depends 
on someone else in ADL, leisure, work and social participation [9]. Participation means to be recognised in the right of being a person and to be involved in society roles $[10,6]$. Over the weeks, bedridden quadriplegic people feel a solitary confinement sensation growing into loss of motivation and loneliness. It affects negatively the rehabilitation phase and the reintegration in community and family context [11]. Several studies showed how the introduction of activities through technological and multimedia tools during the rehabilitation process is important because of their influence on participation [11-14].

An early Occupational Therapy intervention enabled confined to bed people to interact with physical and social environment [15]. Environmental adjustment and assistive technologies, added to physical rehabilitation and the achievement of the awareness of the new self, can reduce the gap between the life before and after the accident, giving a sense of continuity to life as well as reducing the feeling of the patient of being a burden [16,17]. The aim of the present study was to explore quadriplegic bedridden patient's experience about confined to bed period and after an Occupational Therapy treatment to understand if an early Occupational Therapy intervention can improve motivation and participation perception towards environment and people.

\section{Materials and Methods}

\section{Research design/sketch of the research project}

The study was conducted following an exploratory qualitative method. The hermeneutic phenomenology approach was considered as the most adequate way to explore and understand the participants' point of view on their experience in terms of emotions and participation perception. A previous bibliographic research allowed to extrapolate theoretical basis to outline and analyse the field of research, the aim of the study and the most suitable method, starting from the current knowledge on the topic.

\section{Participants}

Each quadriplegic person being hospitalised at Unità Spinale Unipolare of Milan ASST Grande Ospedale Metropolitano Niguarda was eligible to participate. The study recruited people affected by quadriplegia without any other diagnosed neurological deficit who were also available to participate to the Occupational Therapy intervention while bedridden. Patients with no physical deficit to the upper limbs or not interested in the intervention and people that had been confined to bed just for a brief period were excluded from the sample. The sample was composed of 6 people, including 1 female and 5 males, between the age of 12 and 56.

\section{Procedures}

Informatics and multimedia devices were used for the early introduction to the activity. Patients could choose the device (computers, tablets and smartphones) to perform the activity which had been previously determined. In the first place, it was necessary to enable bedridden patients with serious deficit to the upper limbs to interact with physical and social environment. Through environmental adjustment and assistive technologies, an occupational therapist can adapt multimedia devices and modify the bed of the hospital according to the desires and the residual movements of the quadriplegic patient. Besides, technological activities allow to respect the rules of a hospital room. Multimedia devices offer a wide array of choices of possibilities of action and participation.

The research was conducted from February 2016 to September 2016 and each intervention was divided into three phases. The initial phase concerns the first meeting and the set of the treatment. The second phase consists of the environmental adjustment. The occupational therapist had to consider remaining movements and the target of the patient as well as his acceptance of the assistive technology. In the third and last phase, every patient was autonomously able to perform the chosen activity. Entertainment or work occupations (watching TV, reading, phoning friends and parents or keeping in touch with clients, attending classes via Skype, etc.) allowed participants to regain the roles they used to play before the accident.

\section{Data Collection}

At least after a month of the intervention, the participants were asked to answer some questions through a semi-structured interview to make them realise how an early introduction of the activity could influence motivation and the participation perception during the confinement to bed. Patients were interviewed at place and time of their convenience. The aim of the interview was to understand the meaning of the lived experience and investigate the feeling during the acute phase in the Spinal Cord Unit and the aspects which, according to them, improved the perception of participation.

The interview followed the narrative flow of the patient about the initial period of hospitalisation. The interviewer asked for more predetermined questions to focus on the interested topic. Additional questions inquired issues concerning: patients' perception on the work done with the occupational therapist in terms of participation, usefulness of the early introduction of the activity, the importance of multimedia devices during the acute phase and the impact of the activities on a bedridden person. The interviews were audio-recorded, with the prior consent of the participants, transcribed and analysed.

\section{Data Analysis}

Besides verbal components, the analysis of the interviews included notes on non-verbal aspects.

Narrations were arranged in themes and sub-themes with the addition of quotes to highlight the importance of the topic.

\section{Results}

Many themes emerged from the two main issues, the feeling during the confinement to bed and the early introduction of the activity (with the aid of multimedia devices) related to perception of participation. Each theme is followed by the illustrative excerpts transcribed below. Every excerpt is accompanied by the interview's ID number. 


\section{Confined to Bed Period}

\section{Poor concentration}

a. "In the first period I couldn't do things that required a high level of attention, for example reading. It was terrible..." (ID4).

b. "At the beginning I rapidly got tired and being concentrated for a long time was difficult. I couldn't keep concentrated for a long period" (ID2).

\section{Reduced Privacy}

a. My brother checked my emails and Facebook for me. This was a bit embarrassing because the things he read were private. But it was important for me to know what other people wrote to me (ID5).

b. When I had to send messages with my mobile phone I needed my mother to read and answer for me... She looked at my personal things, I had no more privacy (ID3).

\section{Impossibility in doing and Participating and Reduced Possibility to Choose}

a) Laying in bed every day for a month is hard for an active person (ID6).

b) I was depressed because I felt bad and I couldn't do the exercises, when will I be able to move? When will I be able to do all those things the rehabilitation centre offered me that I haven't done yet? (ID5).

c) Sometimes it's as if you are not the one who takes decisions for yourself, for example, choices are automatically made by your family and this makes you feel as if you can't choose, because you are a sick person who can't move, so, consequently, people think you can't take decisions or choose by yourself (ID5).

d) I couldn't do almost anything. My mum fed me at lunchtime and my friends came to help me with the dinner. In effect I could do nothing because they did everything for me (ID1).

e) I was always used to attending my business on my own and, obviously, not being able to solve autonomously minimal problems annoyed me... when you are laid in bed you have a low mobility, and that's why environmental adjustment is so important, like mobile phones and PC supports (ID4).

\section{Emotionally Difficult Phase}

a) I cried a lot because legs and arms didn't work (ID3).

b) For a person who is always active it is hard, terrible (ID6).

c) As the days went on I was demoralised because of the fever and the pain I had. The neck hurt because I had been recently operated. Sometimes pain kept me awake (ID5).

d) That's a crazy shock, it's a madness to be in a situation like that (ID4).

e) The first period of confinement to bed has been the most difficult due to various aches, mainly to tracheotomy (ID1).

\section{Loss of Control}

a) The long-lasting hospitalisation made me freak out, I mean, it makes you lose control... This situation is a crazy shock. In my opinion, adjusting the environment and looking for strategies and assistive technologies for a bedridden person is crucial and essential. Because it's when you find yourself abandoned in the "doing nothing" that leads you into panic (ID4).

b) When I was bedridden in the hospital I lost touch with the world. At the beginning I shut myself in because I said, “I can't do anything with these hands and arms that don't work anymore (ID5).

Activity at the Bed of the Patient (with the aid of multimedia devices)

\section{Re-establishment of contact with physical and social environment}

a) I agreed (to work through Skype to attend classes) because everything was new to me; I had not understood my situation yet, then it was normal to me not to lose any days of school (ID1).

b) I used it (a tablet) specially to read the news because I always kept myself up to date and informed (ID1).

c) I used my mobile phone to call relatives and friends and for work stuff too (ID4).

d) But after you enabled me to use my multimedia devices I got back in touch with the world again. I tried to go back to my previous life. For example, after what happened to me I shut myself in because I feared they wouldn't have accepted me. Being able to talk to them through Skype made me realise I was wrong (ID5).

\section{Functional and Motor Utility}

a) It has been a useful exercise; my movements have improved a lot. I mean, now I can use my PC and I'm able to do accurate and easy movements, while initially it was a challenge (ID5).

b) It's good for the functional point of view too, which means finding strategies to gain some autonomy. So, it's fundamental to take advantage of this period and to avoid postponing because of the confinement to bed (ID4).

c) I would say, both a physical and motivational utility (ID1).

Possibility to Interact and to Work Together with Another Person:

a) Working together with another person has been a nice proposal, because it made me feel good, because being together is a wonderful thing. It helps you not to shut yourself in (smile) (ID6). 
b) When I was bedridden, and you came to me proposing activities through PC you motivated me to do something because before I thought I couldn't do anything anymore (ID5).

c) I appreciated I had been asked what I wanted to do and one of my needs had been welcomed... Instead, if you feel followed and helped in finding strategies, which are not solutions to your disease but a way to go out from your psychological trauma, it is surely a winning strategy. I'm sure of it, because I lived it as a personal experience (ID4).

\section{Possibility to do, Participate and Choose Autonomously}

a. When I was confined to bed I used the tablet to follow school classes through Skype, it enabled me to take notes and watch streaming videos (ID1).

b. I think quadriplegic patients, of every age, should have the possibility to use a computer, it means to work with a participation and leisure view (ID1).

c. Before I used to take photos, it was my hobby. Now I can't take photos anymore, but I can still edit them. I enjoy editing photos for my friends and for myself. It makes me feel good (ID3).

d. According to me these things must be done because they are helpful when you are confined to bed all day long (ID6).

e. Using a computer, you can choose among lots of possibilities: what to do, where to surf the Net, you can order food online and make them deliver to your hospital bed just because you are in the mood. It is not much but it means to have the possibility of choosing based on what you need... you don't depend on someone else and you can decide what to choose, what to do (ID5).

\section{A Dedicated Moment}

a. I used Skype to keep in touch with one of my best friends who was in America and I only could talk to her by Skype (ID1).

b. I could do things I wanted to do on my own, because I was always with my parents (ID2).

\section{Motivation Increment}

a. Slowly, making some tries, adapting the working area, looking for strategies with you one hour a day, all these things motivated me to work on it also on my own (ID5).

b. In this moment of fragility, it really reassures you. When you can do nothing, and you are frightened that you won't be able to do anything anymore, you realise you can still do something (ID4).

c. Thanks to that activity, I met other people and it gave me the encouragement to go on with the rehabilitation... What we did made me understand that you can do things if only you want to, even if you have a problem like mine (ID6). d. Rehabilitation is important to reduce contractions and to move arms and legs. But not only, I'm not dead, I want to live, and my computer allows me to do lots of things (ID3).

\section{Re-establishment of Some Social Roles and Daily Aspects}

a. As soon as I arrived at Niguarda, we started to work through my iPad because my teachers wanted me to attend lessons at any cost via Skype (ID1).

b. My first thought had been to work again on Photoshop, then I decided to change strategy, I mean bureaucracy issues and to keep in touch with my clients. It might be said that since the beginning I have been enabled to carry on some of my daily and normal aspects thanks to environmental adjustment (ID4).

c. I'm going to enrol at Polytechnic of Como which offers the possibility to follow online lessons and to have course material at your disposal. Even if I'll have to stay confined to bed, I'll still be able to go on with my studies. If I weren't enabled to use my computer I would still be telling myself "you can't study anymore... but now everything has changed (ID5).

d. Slowly this activity allowed me to take part in the community life again. You can talk to people who can't see you, so they talk to you without preconceptions. Then I can keep in touch with my family because some of them don't live in Italy. Technology is helpful when you are bedridden because it's as if you can go out of the bed (ID5).

\section{It allows to look at the Future}

a. I'm a computer engineering student and I was afraid I couldn't touch a computer anymore, but after the work we did, I newly want to go on with my studies and specialise myself in software aspects (ID5).

b. It could help me to go on with my studies (ID2).

c. Nowadays, the computer is a fundamental device for everyday life, for school and to work out of here (hospital) (ID6).

\section{Discussion}

This qualitative study offers an overview of the experience of the first period after a Cervical Spinal Cord Injury, highlighting emotional and participation features. In comparison to several studies that have showed the impact of technology on daily living activities and the participation on lives of quadriplegic people $[13,15,16]$, the current one reports the personal experience of long lasting acute bedridden patients, right after the trauma. New and unexpected issues have given the possibility to explore a new field, providing a potential scope of intervention.

Some patients have underlined the decrease of their concentration as consequence of medicines and the difficult emotional phase. Bedridden patients had plenty of time to think about de- 
pending on someone else for the rest of their life. Moreover, they have referred privacy reduction because of parents, friends and healthcare professionals who assist them in every personal aspect, seeming often intrusive and sometimes taking decisions for the patient as if physical disability affected their decision-making ability. These issues influence the loss of the environmental and self-control, causing anger, isolation and concern for the future.

The early introduction of activities with bedridden patients has facilitated the re-establishment of contact with social and physical environment. For the first time after the trauma, through assistive technologies and strategies, people have rediscovered themselves as occupational beings. Technological devices proved to be a good interface to get again in touch with friends in a gradual way, preventing the patient's fear of being judged for his physical aspect and disabilities.

"Functional and motor utility" and "the possibility to have a dedicated moment" have been key elements to increase personal motivation during the confined to bed phase. In addition, finding functional strategies to improve autonomy has helped the patients to relieve from distress due to the difficulties of movement. The interaction with the occupational therapist allowed each patient to be an active character of his own rehabilitation process. For this reason, the entire sample has perceived an enhancement of the possibility to participate in terms of interaction and decisionmaking ability, experiencing a reduced dependence feeling. Consequently, this issue has allowed the promotion of three more aspects which positively influenced each other: increment of motivation, re-establishment of some social roles and daily aspects (such as being a student, worker, friend, son) and the opportunity to look at the future with a more positive attitude.

\section{Conclusion}

In conclusion, to set the rehabilitation process of a quadriplegic bedridden person it is necessary to know his personal needs, roles and habits. Concomitantly with the usual treatment, it is important to focus on patient's participation, to reduce the sense of isolation. Specifically, environmental adjustment, specific assistive technologies, strategies and cooperation, prove to be useful to introduce activities that enhance motivation and perception of participation.

Finally, there are some limitations of this study that should be discussed. Firstly, the sample of the study wasn't numerically significant. Secondly, the work has been conducted in just one hospital. In every qualitative study the results can't be judged as generalizable, but the outcome has given the basis to proceed with further quantitative studies.

\section{References}

1. Furlan JC, Sakakibara BM, Miller WC, Krassioukov AV (2013) Global incidence and prevalence of traumatic spinal cord injury. Can J Neurol Sci 40(4): 456-464.

2. Devivo M (2012) Epidemiology of traumatic spinal cord injury: trends and future implications. Spinal Cord 50(5): 365-372.

3. Scivoletto G, Di Lucente L, Ugo Fuoco, Valentina Di Donna, Letizia Laurenza, et al. (2008) Riabilitazione e valutazione dei pazienti mielolesi: l'esperienza della Fondazione S. Lucia di Roma. Rapporti ISTISAN Pp: 108.

4. Wilcock A, Hocking C (1998) An occupation perspective of Health. Thorofare (NJ) Slack Incorporated, London.

5. (1986) World Health Organization, Health and Welfare Canada. Canadian Public Health Association, Ottawa (CA): Ottawa Charter for Health Promotion, Canada.

6. (2001) World Health Organization. "International Classification of Functioning, Disability and Health: ICF, Geneva: WHO, Switzerland.

7. Hemmingsson H, Jonsson H (2005) An Occupational Perspective on the Concept of Participation in the International Classification of Functioning, Disability and Health, Some Critical Remarks. Am J Occup Ther 59(5): 569-576.

8. Pulaski KH (1988) Neurological deficits in adult age. HL Hopkins, HD Smith (Eds.), Willard and Spackman's occupational therapy. Philadelphia: Lippincott, Pennsylvania.

9. (2006) United Nations Convention on the Rights of Persons with Disabilities New York: (CRPD), New York.

10. Starrost K, Lotze M (2015) Consequences of bed rest and immobilization. Neuroreha.

11. Van Laere M, Duyvejonck R (1986) Environmental Control and Social Integration of a High-lesion Tetraplegic Patient: Case Report. Paraplegia 24(5): 322-325.

12. Linden A, Lexell J, Lund ML (2010) Perceived difficulties using everyday technology after acquired brain injury: Influence on activity and participation. Scand J Occup Ther 17(4): 267-275.

13. Rigby P, Ryan S, Joos S, Cooper B, Jutai JW, et al. (2005) Impact of Electronic Aids to daily Living on the Lives of Person with Cervical Spinal cord injuries. Assistive Technol 17(2): 89-97.

14. Seplowitz C (1984) Technology and Occupational Therapy in the Rehabilitation of the bedridden Quadriplegic. Am J Occup Ther 38(11): 743-747.

15. (2004) Linee guida per le Unità spinali unipolari [Guidelines for spinal cord units]. Conferenza Stato-Regioni.

16. Balcisero MG, Maselo L (2001) Dal trauma alla riabilitazione: Vissuti psicologici individuali e rilevanza del contesto relazionale circostante. Un'ipotesi di progetto integrato per l'Unità Spinale. Verona 2000: Spinal Cord injuries Animation Group. Italian.

17. Burnham L, Werner G (1978) The High-level Tetraplegic: Psychological Survival and Adjustment. Paraplegia 16(2): 198-192. 

Co This work is licensed under Creative
Commons Attribution 4.0 License
DOI: 10.19080/PBSIJ.2018.10.555779

\section{Your next submission with Juniper Publishers} will reach you the below assets

- Quality Editorial service

- Swift Peer Review

- Reprints availability

- E-prints Service

- Manuscript Podcast for convenient understanding

- Global attainment for your research

- Manuscript accessibility in different formats

( Pdf, E-pub, Full Text, Audio)

- Unceasing customer service

Track the below URL for one-step submission https://juniperpublishers.com/online-submission.php 